\title{
ARTICLE SARS-CoV-2 receptor binding domain radio-probe: a non-invasive approach for angiotensin-converting enzyme 2 mapping in mice
}

\author{
Dan $\mathrm{Li}^{1}$, Jin Ding ${ }^{1}$, Te-li Liu ${ }^{1}$, Feng Wang ${ }^{1}$, Xiang-xi Meng ${ }^{1}$, Song Liu ${ }^{1}$, Zhi Yang ${ }^{1}$ and Hua Zhu ${ }^{1}$
}

The spike protein of SARS-CoV-2 interacts with angiotensin-converting enzyme 2 (ACE2) of human respiratory epithelial cells, which leads to infection. Furthermore, low-dose radiation has been found to reduce inflammation and aid the curing of COVID-19. The receptor binding domain (RBD), a recombinant spike protein with a His tag at the C-terminus, binds to ACE2 in human body. We thus constructed a radioiodinated RBD as a molecule-targeted probe to non-invasively explore ACE2 expression in vivo, and to investigate radiotherapy pathway for inhibiting ACE2. RBD was labeled with $\left[{ }^{124} \mathrm{I}\right.$ ]Nal using an N-bromosuccinimide (NBS)-mediated method, and ${ }^{124} \mathrm{I}-\mathrm{RBD}$ was obtained after purification with a specific activity of $28.9 \mathrm{GBq} / \mathrm{nmol}$. Its radiochemical purity was (RCP) over $90 \%$ in saline for 5 days. The dissociation constant of ${ }^{124}$ I-RBD binding to hACE2 was $75.7 \mathrm{nM}$. The uptake of ${ }^{124}$ I-RBD by $\mathrm{HeLa}^{\mathrm{ACE}+}$ cells at $2 \mathrm{~h}$ was $2.96 \% \pm 0.35 \%$, which could be substantially blocked by an excessive amount of RBD, and drop to $1.71 \% \pm$ $0.23 \%$. In BALB/C mice, the biodistribution of ${ }^{124} \mathrm{I}-\mathrm{RBD}$ after intravenous injection showed a moderate metabolism rate, and its $24 \mathrm{~h}$ post injection (p.i.) organ distribution was similar to the expression profile in body. Micro-PET imaging of mice after intrapulmonary injection showed high uptake of lung at 1, 4, $24 \mathrm{~h}$ p.i.. In conclusion, the experimental results demonstrate the potential of ${ }^{124} \mathrm{I}-\mathrm{RBD}$ as a novel targeted molecular probe for COVID-19. This probe may be used for non-invasive ACE2 mapping in mammals.

Keywords: SARS-Cov-2; receptor binding domain; radio-probe; iodine isotopes; angiotensin-converting enzyme 2

Acta Pharmacologica Sinica (2022) 43:1749-1757; https://doi.org/10.1038/s41401-021-00809-y

\section{INTRODUCTION}

The outbreak of coronavirus disease 2019 (COVID-19) at the end of 2019 led to a global pandemic caused by severe acute respiratory syndrome coronavirus type 2 (SARS-CoV-2). It has become a severe public health crisis globally till now (October 2021). Since the spread of the disease, several experimental antiviral drugs, such as remdesivir, have gradually entered the clinical trial stage, but the death toll still soared [1]. On June 12, 2021, the USA media reported the effect of the first low-dose treatment for severely ill COVID-19 patients conducted by Radiation Oncology at Emory University School of Medicine. Welsh and colleagues from Beaumont Health, Ohio State University, Baptist Health Miami, and Barrow Neurological Institute, have already published an article on the basic science behind this method [2]. The results showed that low-dose radiation reduced inflammation and promoted healing of COVID-19. In addition to vaccines, neutralizing antibodies and small molecule antivirals drugs are interventional tools that are expected to reduce the severe and fatality rate of COVID-19, but there is still no satisfactory products available.

The mechanism by which SARS-CoV-2 infects the body is complicated, including many interactions among different molecular pathways between the virus and the host cells. Angiotensinconverting enzyme 2 (ACE2) is a homologue of carboxypeptidase
$A C E$, and the main active peptide of the renin-angiotensin system (RAS). Zhao et al. found that, SARS-CoV-2 infects human respiratory epithelial cells through the interaction of S-protein and human ACE2 [3]. Later, Markus Hoffmann et al. released a related study on BioRxiv, showing that SARS-CoV-2 infects through the same ACE2 receptor as does SARS coronavirus, and employs the cell protease TMPRSS2 used for SARS-CoV-2 [4, 5]. Since ACE2 is the only entrance through which SARS-CoV-2 invades cells, it is particularly important to develop clinical drugs that target and inhibit viral entry as early as possible.

Spike protein is the most important envelope protein of coronavirus, which includes two subunits, S1 and S2. S1 is mainly comprised of the receptor binding domain (RBD), which is responsible for identifying cell receptors. Spike protein specifically binds to ACE2 on human respiratory epithelial cells, and the SARSCoV-2 infects human lung tissue and other organs. The specific binding of ACE2 and RBD is not only the key to the SARS-CoV-2 virus invading pathway, but also implies the opportunity to cure other diseases involving ACE2.

In recent years, modern molecular imaging techniques and radiopharmaceuticals have become indispensable when it comes to targeted drugs. The in vivo, real-time and non-invasive advantages of modern molecular imaging techniques are self-

\footnotetext{
${ }^{1}$ Key Laboratory of Carcinogenesis and Translational Research (Ministry of Education/Beijing), NMPA Key Laboratory for Research and Evaluation of Radiopharmaceuticals (National Medical Products Administration), Department of Nuclear Medicine, Peking University Cancer Hospital \& Institute, Beijing 100142, China Correspondence: Zhi Yang (pekyz@163.com) or Hua Zhu (zhuhuananjing@163.com)

These authors contributed equally: Dan Li, Jin Ding
}

Received: 21 June 2021 Accepted: 28 October 2021

Published online: 23 November 2021 
evident when compared with traditional diagnostic techniques for infection diseases, including immunodiagnosis, immunofluorescence, microscopy, microbiology cultures, and molecular techniques (nucleic acid amplification and mass spectrometry) [6, 7]. For molecular targeted internal radiation therapy, the type of radioactive decay is critical. Radiolabeled probes involving ${ }^{125} \mathrm{I},{ }^{177} \mathrm{Lu}$ and ${ }^{225}$ Ac have been gradually applied in clinical radiotherapy and received extensive attention [8].

There are many sister radio-active isotopes of iodine, among which ${ }^{123} \mathrm{I},{ }^{125} \mathrm{I}$, and ${ }^{131} \mathrm{I}$ are well known radionuclides most commonly applied in clinical nuclear medicine. ${ }^{124} \mathrm{I}$, a novel positron-emitting medical nuclide, is in-house cyclotron-produced and available for long-range transportation. While iodine isotopes $\left({ }^{123 / 124 / 125 / 131}\right.$ I) can make a significant impact on single nucleotide mutations, it has little direct effect on the double-stranded structure of DNA [9]. This property of iodine isotopes helps to kill or inhibit the replication of viruses in cells, with minimum impact on normal cells. To achieve this goal, it is obviously an excellent method to use ${ }^{124}$-labeled targeting probes and ACE2-specific binding agents to precisely locate ACE2 target.

As a specific virus origin, single-chain variable fragment (ScFv) RBD could serve as a delivery agent for ${ }^{124}$. The ScFv directly and specifically targets human ACE2, making it an ideal probe to elaborate virus vector-human receptor relationship. In this article, we constructed an ${ }^{124}$ I labeled RBD as a molecular probe, which is available for both in vivo, real-time, non-invasive imaging of SARSCoV-2 invasion of the body, and as a potential preventive and therapeutic drug for COVID-19. Further in-depth research may be of greater significance as a new supplement to the prevention and treatment of COVID-19.

\section{MATERIALS AND METHODS}

Ethical statement

All animal studies were performed according to the guidelines established by the Peking University Cancer Hospital Animal Care and Use Committee, and approved Protocol Numbers are 20190006 and $20-0183$.

\section{General}

All reagents were obtained from commercial vendors and used without any further purification. Phosphate buffer ( $\mathrm{PB}, 0.1 \mathrm{M}, \mathrm{pH} 7.0)$, phosphate buffer saline (PBS, $0.01 \mathrm{M}, \mathrm{pH} 7.4$ ) and carbonate buffer (0.1 M, pH 9.5) were purchased from Aladdin, Shanghai, China. Recombinant SARS-CoV-2 spike RBD-His-Avi (host cell RBD) with Nterminal His tag (Catalog \# BP003052) and human ACE2-His-Avi (Catalog \# BP003061) were purchased from Syd Labs, Boston, Massachusetts, USA. N-Bromosuccinimide (NBS, $0.1 \mathrm{M}$ ) was obtained from Sigma-Aldrich Chemie $\mathrm{GmbH}$, Steinheim, Germany (Catalog \# B9252). Human Serum Albumin (10\%) was purchased from CSL Behring AG, Bern, switzerland (Catalog \# B14200811350). PD-10 columns were from GE Healthcare, Buckinghamshire, England (catalog \# 17001651). The isotope ${ }^{124}$ I was self-produced by our laboratory using ${ }^{124} \mathrm{Te}(\mathrm{p}, \mathrm{n}){ }^{124} \mathrm{I}$ nuclear reaction, the activity concentration is $370 \mathrm{kBq} / \mu \mathrm{L}$, and the production situation is detailed in the literature [10]. The 96-well polystyrene Stripwell ${ }^{\mathrm{TM}}$ microplate was purchased from Corning Costar, New York, USA (Catalog \# 2481); radioactive thin layer chromatography scanner (radio-TLC) was from Bioscan, Poway, California, USA (Type \# AR2000); the Hypersil BDS C-18 reverse chromatographic column $(5 \mu \mathrm{m}, 250$ $\mathrm{mm} \times 4.6 \mathrm{~mm}$ ) was from YMC Co., Ltd, kyoto, Japan. Fully automatic gamma counter was from Perkin Elmer, Waltham, Massachusetts, USA (Type \# Wizard2). The radioactivity measurement activity meter was from Capintec, Ramsey, New Jersey, USA (Type \# CRC-25R).

Surface plasmon resonance (SPR)

The SPR study was performed using Biacore T200. A temperature of $25^{\circ} \mathrm{C}$, flow rate of $10 \mu \mathrm{L} / \mathrm{min}$ and a PBS running buffer were used for all experiments. Contact time was $420 \mathrm{~s}$. The carboxymethylated sensorchip surface of CM5 chip (Biacore) was activated by NHS/EDC, and then hACE2 was immobilized in acetate buffer ( $\mathrm{pH} 4.5$, Biacore). RBD was diluted to $100 \mathrm{nM}$ with buffer as the highest injection concentration. Seven concentration gradients, including $50,25,12.5,6.25,3.125,1.56$ and $0.78 \mathrm{nM}$, were fixed on the surface of CM5 chip. The $K_{\mathrm{D}}$ value was obtained by affinity fitting.

Generate stable ACE2 overexpression HeLa and HepG2 cells In order to verify the affinity of RBD and ACE2 at the cellular level, we commissioned Ubigene to generate cells with ACE2 overexpression, including HeLa ${ }^{\mathrm{ACE} 2+}$ and $\mathrm{HepG} 2{ }^{\mathrm{ACE} 2+}$ cells. According to the gene expression, compared with HeLa cell line, the expression rate of HeLaACE2+ cell line was much higher.

\section{Radiosynthesis}

A total $3.2 \mu \mathrm{mol}$ of RBD protein solution $(100 \mu \mathrm{L}, 1.0 \mathrm{mg} / \mathrm{mL})$ was added to $500 \mu \mathrm{L}$ of $0.1 \mathrm{M} \mathrm{PB}(\mathrm{pH} 7.0$ ) to a culture tube (vacuum flask). 44.4 MBq of [ $\left.{ }^{124} \mathrm{I}\right] \mathrm{Nal}$ (in $500 \mu \mathrm{L}$ of $0.1 \mathrm{M} \mathrm{NaOH}$ ) was added to the tube. Then $12 \mu \mathrm{L}$ NBS $(1.0 \mathrm{mg} / \mathrm{mL})$, as an oxidant, was added to the tube and the mixture was allowed to react for $1 \mathrm{~min}$ at room temperature. After that, $100 \mu \mathrm{L} 5 \%$ human serum album was added to terminate the reaction. Then the mixture was loaded onto a PD-10 column preconditioned with $2.5 \mathrm{~mL}$ PBS. Before and after purification, the solutions were measured using SG-ITLC paper with saline as the eluent. The radiolabeled RBD was purified using $0.01 \mathrm{M}$ PBS as the eluent.

\section{Enzyme-linked immunosorbent assay (ELISA)}

Enzyme-linked immunosorbent assay (ELISA) was used to determine the binding potency between RBD and ACE2. Firstly, the recombinant protein of ACE2 was dissolved in $0.1 \mathrm{M}$ carbonate buffer ( $\mathrm{pH} 9.5$ ) to $1 \mu \mathrm{g} / \mathrm{mL}$; and $50 \mu \mathrm{L}$ of the solution was added to each well coated with 96 -well polystyrene Stripwell ${ }^{\mathrm{TM}}$ microplate, $4{ }^{\circ} \mathrm{C}$, overnight. Then the antigen solution was discarded, and washed three times with 0.01 M PBS ( $\mathrm{pH} 7.4)$. After that, 50-200 $\mu \mathrm{L}$ $5 \%$ powdered milk (diluted with PBS) per well was added to the microplate for $2 \mathrm{~h}$ at room temperature to block other non-specific sites. Then antigen solution was discarded similarly after washing five times with $0.01 \mathrm{M}$ PBS ( $\mathrm{pH}$ 7.4). When the ACE2 plates were ready, ${ }^{124}$ I-RBD was added with six concentration gradients, 9.25, $18.5,37,74,185$ and $370 \mathrm{kBq}, 50 \mu \mathrm{L}$ per well. Five parallels were set for each concentration gradient and were incubated for $2 \mathrm{~h}$ at $37^{\circ} \mathrm{C}$. Finally, each incubation well was cut and analyzed by a fully automatic gamma counter.

\section{Cell uptake}

Cells of HeLa and $\mathrm{HeLa}^{\mathrm{ACE} 2+}$ cells $\left(5 \times 10^{4}\right)$ were respectively added to each of the 24-well plates, then cultured overnight to make sure the cells stick to the wall. After replacing the serum- free medium, $74 \mathrm{kBq}$ ${ }^{124} \mathrm{I}$-RBD was added to each well and meanwhile $20 \mu \mathrm{g}$ RBD was added as the blocker at $2 \mathrm{~h}$. It was incubated at $37^{\circ} \mathrm{C}$ for $5,30,60$ and $120 \mathrm{~min}$ (120 min blocker) to terminate the reaction. After washed with PBS for three times, the cells were lysed with cell lysate and collected for $\gamma$-Counter test. $1 \%(0.74 \mathrm{kBq})$ of applied ${ }^{124} \mathrm{I}$-RBD was used as marker to test by $\mathrm{Y}$-Counter.

\section{Western blot analysis}

Vital organs removed from normal mice were crushed with a mortar using liquid nitrogen under ice cold conditions and lysed with RIPA lysis buffer (YEASEN, \#20101ES60) and InStab ${ }^{\text {Tm }}$ Protease Cocktail, EDTA-free, mini, tablet-form (YEASEN, \#20123ES10). After centrifugation at $14,000 \mathrm{r} / \mathrm{min}$ at $4{ }^{\circ} \mathrm{C}$ for $20 \mathrm{~min}$, supernatants were collected and protein concentration was determined using the Pierce ${ }^{\mathrm{m}} \mathrm{BCA}$ protein assay. All samples were heated for $10 \mathrm{~min}$ at $95^{\circ} \mathrm{C}$ in $5 \times$ SDSPAGE Protein Loading Buffer (YEASEN, \#20315ES05) before loading. Cell lysate aliquots were separated in $10 \%$ SDS-PAGE (SDS-PAGE Gel 
Preparation Kit, YEASEN, \#20328ES50). Proteins were electro-blotted onto polyvinylidene fluoride membranes (Millipore) and blocked by incubation with TBST (TBS and $0.2 \%$ Tween-20) containing 5\% nonfat dry milk for $1 \mathrm{~h}$ at room temperature. After blocking, membranes were washed in TBST three times for $5 \mathrm{~min}$ and then probed with the Recombinant Anti-ACE2 Momoclonal Antibody (Abcam, \#ab108252) overnight at $4^{\circ} \mathrm{C}$. Subsequently, the membranes were washed with TBST and incubated for $1 \mathrm{~h}$ at room temperature with goat-anti rabbit-HRP (Servicebio, \#GB23303) in TBST. Finally, membranes were washed three times and enhanced with Clarity ${ }^{\mathrm{m}}$ Western ECL substrate (YEASEN, \#36208ES60), followed by imaging with Alliance Micro Q9 (UVITEC).

\section{ACE2 high expression tumor model}

ACE2 high expression tumor model with HepG2 $2^{\text {ACE2+ }}$ cells was established in immunodeficiency BALB/c nude mice (Huafukang, Beijing). HepG2 $2^{\mathrm{ACE} 2+}$ cells $\left(1 \times 10^{6}\right)$ were implanted subcutaneously in the right armpit of BALB/c nude mice. And mice were analyzed when the tumors reached a diameter of $10 \mathrm{~mm}$.

\section{Micro-PET imaging}

Normal KM mice or HepG2 $2^{\mathrm{ACE} 2+}$ model nude mice were injected with $3.7 \mathrm{MBq}$ of ${ }^{124} \mathrm{I}-\mathrm{RBD}$ via tail vein. Then $10 \mathrm{~min}$ static PET scans were acquired at each time point $0.5,2,24$, and $60 \mathrm{~h}$ post injection (p.i.), respectively. Using a small-animal PET/CT scanner (Super Nova PET/CT, Pingseng Healthcare, China), the PET images were reconstructed by Avatar 3 and the ROl-derived standard uptake value (SUV) was calculated by drawing ROls over these organs.

Normal KM mice were injected with $0.74 \mathrm{MBq}^{124} \mathrm{I}-\mathrm{RBD}$ and free $\left[{ }^{124} \mathrm{I}\right] \mathrm{Nal}$ via endotracheal and intrapulmonary injection, followed by PET/CT imaging at 1, 4, 24, and $48 \mathrm{~h}$ p.i. The specific procedures for intrapulmonary administration are shown in Supplementary Fig. S1. The mice were anesthetized by intraperitoneal injection of $0.2 \mathrm{~mL} 4 \%$ chloral hydrate and located on a board with a string attached to their maxillary teeth. The mouse' neck was illuminated with a cold light to show the entrance of the trachea. Then the tongue was pulled out of the mouth by a tweezer and the root of the tongue was pressed by a tongue depressor. It is easy to see the epiglottis as an open and close bright dot. That is the trachea entrance. The mouse tracheal catheter was inserted into the trachea, $0.05-0.1 \mathrm{~mL}$ agent was slowly pushed in it with a syringe. After the catheter was removed, the mice were then suspended for another $10 \mathrm{~min}$ before being placed in the cage.

Biodistribution

$\mathrm{BALB} / \mathrm{c}$ male mice were intravenously injected with $200 \mu \mathrm{L}$ ${ }^{124}$ I-RBD (0.74 MBq) via tail vein. The mice were sacrificed in groups by cervical dislocation at $0.5,2,24$ and $60 \mathrm{~h}$ p.i.. The main organs, including heart, liver, lung, kidneys, spleen, stomach, bone, muscle, intestines, brain and blood, were collected, weighed and measured for the radioactivity by $\gamma$-counter. As a standard, ten samples of $1 \%$ injected dose were taken out and measured. The results were expressed as the percent of injected dose per gram (\%ID/g).

Human organ radiation dosimetry estimates

The biodistribution data of ${ }^{124} \mathrm{I}-\mathrm{RBD}$ in BALB/C mice were used for estimating the human organ radiation dosimetry of ${ }^{124}$ I-RBD using the OLINDA/EXM 2.0 package with the model of adult male. We supposed that ${ }^{123 / 124 / 125 / 131}$ I-RBD hold a similar biodistribution in mice, so the radiation dosimetry of ${ }^{123 / 125 / 131}$ I-RBD was estimated.

\section{Statistical analysis}

The data are expressed as the mean \pm SD. Independent sample $t$-tests were used to compare SUVmean values between different groups. $P$ values $<0.05$ were considered significant. Statistical analyses were performed with SPSS software (V.26.0, SPSS) and Prism (V8.0, GraphPad Software).

\section{RESULTS}

Radio-chemical quality control of ${ }^{124} \mathrm{I}-\mathrm{RBD}$

${ }^{124}$ I-RBD was manually prepared with a radiochemical yield of $83.9 \% \pm 4.6 \% \quad(n=10$, non-decay corrected). Radio-TLC assay showed that the radiochemical purity (RCP) of ${ }^{124}$ I-RBD was more than $99 \%$ (Fig. 1d). The specific activity was between 25.3 and $28.9 \mathrm{GBq} / \mathrm{nmol}$. After incubation in saline (room temperature, $120 \mathrm{~h}$ ) or $5 \%$ human serum albumin (room temperature, $120 \mathrm{~h}$ ), a single peak (over $99 \% \mathrm{RCH}$ ) was observed on the radio-TLC chromatogram (Fig. 1d), indicating that ${ }^{124}$ I-RBD was stable in vitro at least for 5 days. The ${ }^{124}$ I-RBD solution was colorless and clear. The quality control result is shown in Table 1.

Biological evaluations of ${ }^{124} \mathrm{I}-\mathrm{RBD}$

The binding ability of RBD to human ACE2 receptor was studied by SPR binding studies. Affinity model was applied to fit the data and to calculate the dissociation constants, $K_{\mathrm{D}}=14.08 \mathrm{nM}$ (Fig. 2). The binding potency of ${ }^{124}$ I-RBD to human ACE2 was detected by the ELISA method, with the dissociation constants, $K_{\mathrm{D}}=75.7 \mathrm{nM}$ (Fig. 1b). The results showed that RBD has a high affinity with hACE2 in vitro.

Compared with non-transduced HeLa cell line, the ACE2 gene expression rate of $\mathrm{HeLa}^{\mathrm{ACE} 2+}$ cell line was 561.2 times higher. Western blot analysis showed that HeLaACE2+ cell did have high expression of ACE2 (Supplementary Fig. S3). Cell uptakes of radiotracers are summarized in Fig. $1 \mathrm{c}$. Results showed that at $2 \mathrm{~h}$, the uptake values of ${ }^{124} \mathrm{I}-\mathrm{RBD}$ in HeLa ${ }^{\mathrm{ACE} 2+}$ cells were $(2.96 \pm 0.35) \%$ ID $/ 10^{6}$ cells without blocking and $(1.71 \pm 0.23) \% \mathrm{ID} / 10^{6}$ cells with cold RBD $(P=0.00038)$; the uptake values of ${ }^{124} \mathrm{I}$-RBD in HeLa cells were $(1.96 \pm 0.22) \% \mathrm{ID} / 10^{6}$ cells without blocking and $(1.64 \pm 0.15) \% \mathrm{ID} / 10^{6}$ cells with cold RBD $(P>0.05)$ (Fig. 1c).

Micro-PET imaging of ${ }^{124} \mathrm{I}-\mathrm{RBD}$ and ACE2 mapping

The representative PET images of normal mice at 0.5, 2, 24, $60 \mathrm{~h}$, after intravenous injection of $3.7 \mathrm{MBq}{ }^{124} \mathrm{I}$-RBD were shown in Fig. 3. We observed the typical enterohepatic metabolism and stomach uptake of ${ }^{124}$ I-RBD.

As shown in Fig. 3, ${ }^{124}$ I-RBD mainly accumulated in liver, kidneys and blood, with the uptake values of $(14.76 \pm 3.85),(14.54 \pm 3.16)$ and $(12.22 \pm 2.58) \% \mathrm{ID} / \mathrm{g}$ at $1 \mathrm{~h}$ p.i. (p.i.), respectively, and followed by lung, heart, spleen and large intestine. It rapidly cleared out from most organs with low uptake at $24 \mathrm{~h}$ p.i. and $60 \mathrm{~h}$ p.i.. While the uptake of ${ }^{124} \mathrm{I}-\mathrm{RBD}$ in small intestine was increased between $1 \mathrm{~h}$ p.i. and $2 \mathrm{~h}$ p.i., and decreased at $24 \mathrm{~h}$ p.i. by $96.7 \%$.

In order to research the retention of RBD in the lung, we adopted the method of intrapulmonary transbronchial administration, and injected $0.927 \mathrm{MBq}{ }^{124} \mathrm{I}-\mathrm{RBD}$ in a volume of about $50 \mu \mathrm{L}$. The micro-PET imaging results were shown in Fig. 4.

PET/CT imaging of normal mice was performed after normal mice were injected with ${ }^{124}$ I-RBD via endotracheal and intrapulmonary injection, and the results showed high uptake of lung, stomach and thyroid (Fig. 4a). SUV of each organ measured by outlining the target area of interest was shown in Fig. $4 \mathrm{c}$. After $4 \mathrm{~h}$, the $\mathrm{SUV}_{\text {mean }}$ in lung and kidney was $4.9 \pm 0.49$ and $0.21 \pm 0.06$, respectively, and the ratio of lung to kidney was 23.73 (Fig. 5c). After $24 \mathrm{~h}$, the SUV $\mathrm{V}_{\text {mean }}$ in lung and kidney was $0.53 \pm 0.04$ and $0.03 \pm 0.01$, respectively, and the ratio of lung to kidney was 19.88 . The same dose of $\left[{ }^{124} \mid\right] \mathrm{Nal}$ was injected via endotracheal and intrapulmonary injection in normal mice (Fig. 4b, d), and the results showed the lower uptake in lung at $4 \mathrm{~h}$, the SUV $\mathrm{V}_{\text {mean }}$ in lung and kidney was $0.16 \pm 0.01$ and $0.29 \pm 0.10$, respectively, the ratio of lung to kidney was 0.55 . Even at $1 \mathrm{~h}$, the uptake of $\left[{ }^{[24}{ }_{1}\right] \mathrm{Nal}$ in the lungs was relatively lower (Fig. 5b, d), which was removed by blood metabolism soon. The SUV in lung after injection with $\left[{ }^{124} I\right] \mathrm{Nal}$ was $0.4 \pm 0.04$, while the SUV in lung after injection with ${ }^{124} \mathrm{l}-\mathrm{RBD}$ was $6.70 \pm 0.33$.

As shown in Fig. 5a, we can find out ${ }^{124} I-R B D$ resided in the lung organ for long time, while the $\left[{ }^{124}\right] \mathrm{I}$ Nal almost disappeared in the lungs $1 \mathrm{~h}$ after the injection. Meanwhile, verified by 
a

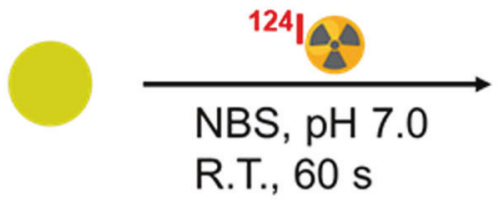

RBD

R.T., $60 \mathrm{~s}$
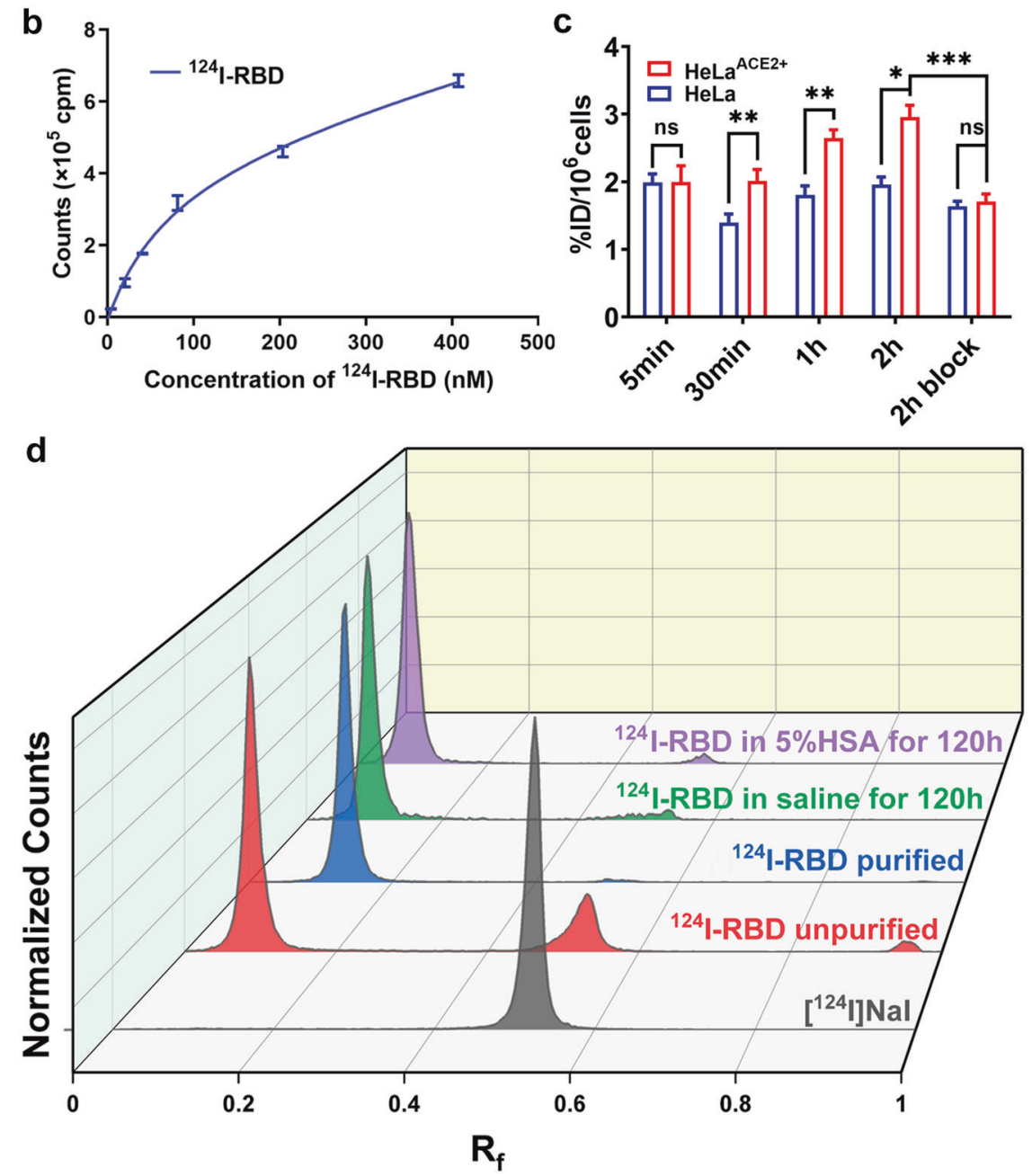

Fig. 1 Quality control and biological evaluation of ${ }^{124}$ I-RBD. a Labeling of RBD with $\left[{ }^{124}\right.$ I] lodine; $\mathbf{b}$ Binding affinity assay of ${ }^{124}$ I-RBD to ACE2. ACE2 was exposed to increasing concentrations of ${ }^{124}$ I-RBD. $c$ The cellular uptake of ${ }^{124} \mathrm{I}$-RBD in HeLa and HeLa ${ }^{A C E 2+}$ cells respectively. ns represent no statistically significant difference, ${ }^{*} P<0.05,{ }^{* *} P<0.01,{ }^{* * *} P<0.001$. d TLC results of purified ${ }^{124}$ I-RBD and radiochemical purity of ${ }^{124} \mathrm{I}-\mathrm{RBD}$ at $120 \mathrm{~h}$ after labeling showed high in vitro stability.

\begin{tabular}{|lll|}
\hline Table 1. & Quality control of ${ }^{124} \mathrm{I}-\mathrm{RBD}$. \\
\hline Parameter & QC specfication & QC result \\
\hline Appearance & Clear, colorless & Pass \\
Volume & $1-2 \mathrm{~mL}$ & $1 \mathrm{~mL}$ \\
$\mathrm{pH}$ & $5.0-8.0$ & 7.4 \\
Radiochemistry purity & $>95 \%$ & $>99 \%$ \\
Ethanol & $<5 \%$ & $<5 \%$ \\
Endotoxins & $<15 \mathrm{EU} / \mathrm{mL}$ & $<5 \mathrm{EU} / \mathrm{mL}$ \\
Sterility & Sterile & Pass \\
Specific activity & $18.5-296 \mathrm{GBq} / \mathrm{nmoL}$ & $25.3-28.9 \mathrm{GBq} / \mathrm{nmoL}$ \\
\hline
\end{tabular}

immunohistochemistry (Fig. 5e), ACE2 expresses in the lungs of mice. It is possible to demonstrate that it is the targeting of RBD to ACE2 in the lungs that allows ${ }^{124}$ I-RBD to stay for a long time.

As illustrated in Fig. 6a, we evaluated both the liver hepatocellular carcinoma HepG2 and the HepG2 with high endogenous ACE2 expression to simulate the distribution, kinetics and targeted uptake of ${ }^{124} \mathrm{I}-\mathrm{RBD}$ PET at human-ACE2 sites in vivo. The percent injected activity/mL (by SUV mean value) of ${ }^{124}$ I-RBD accumulated in heart, liver, lung, kidney, stomach, intestine, muscle and tumor at 0.5, 1, 2, 4,24 and $48 \mathrm{~h}$ were quantified by using micro-PET imaging (Fig. $6 \mathrm{c}$ ). HepG2 ${ }^{\text {ACE2 }+}$ tumor showed $2.34 \mathrm{SUV}_{\text {mean }}$ at $0.5 \mathrm{~h}$, and the result at $24 \mathrm{~h}$ was ten times as muscle uptake (0.067 vs 0.0067$)$. Compared to HepG2, the uptake in HepG2 ${ }^{A C E 2}$ was significantly higher at each time point. 
Western blot results showed the gray value ratios of ACE2 to $\beta$ actin in small-intestine and kidney are more than 1.0, indicating the high expression of ACE2. By contrast, the ratio in heart, liver, lung and stomach was lower than 1.0 (Supplementary Fig. S4). The results are somewhat similar to that shown in The Human Protein Atlas (http://www.proteinatlas.org/).

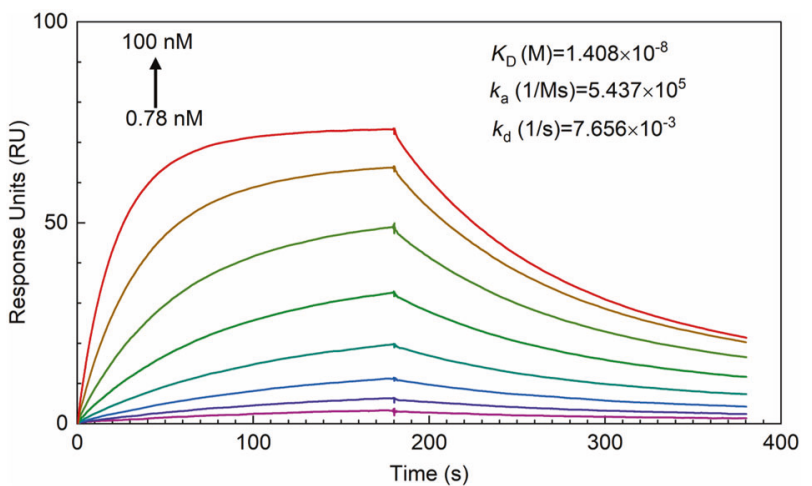

Fig. 2 SPR Response Units [RU] at equilibrium as a function of the concentration of RBD, using immobilized ACE2 as receptor. Affinity model was applied to fit the data and to calculate the dissociation constants. The peptides RBD binds to ACE2 with dissociation constants $K_{\mathrm{D}}=14.08 \mathrm{nM}$.

\section{DISCUSSION}

It is well known that SARS-CoV-2, as an RNA virus, has a short mutation cycle and a wide variety of strains. This makes it particularly difficult to develop antibodies that target the virus and finally achieve clinical transformation after long trials. Unlike SARS-CoV-2, the physiological activity and distribution of ACE2, another key component of the virus' cellular pathway, keeps stable in body.

The development of inhibitor probes targeting ACE2 is more reasonable in theory, and more possible in practice than antibody drugs targeting the virus itself. RBD is the intermediate between virus and ACE2 receptor. We proposed that the modification of RBD with PET radionuclide may give some characters of the SARS-CoV-2's deadly entry. Using advanced PET technology to monitor the labeled RBD's metabolism and rsidual may provide a comprehensive viewpoint of SARS-CoV-2's infections in animal.

Here, we successfully constructed ${ }^{124} I-R B D$, for the first time, and validated its radiochemical characters. Based on these radiochemical evaluations, ${ }^{124}$ I-RBD is feasible to produce and reliable for further application. We hypothesize that the ${ }^{124}$ I-RBD can be used for non-invasive ACE2 mapping in body. According to the binding assays of RBD to human ACE2 receptor, these results prove the high affinity and selectivity of ${ }^{124}$ I-RBD antibody against ACE2. After ${ }^{124}$ I-RBD was injected into mice through tail vein, it was mainly metabolized through kidney and urinary system. The stomach showed high uptake in the first $24 \mathrm{~h}$, which may be ascribed to the specific uptake of free iodine by the stomach [12].

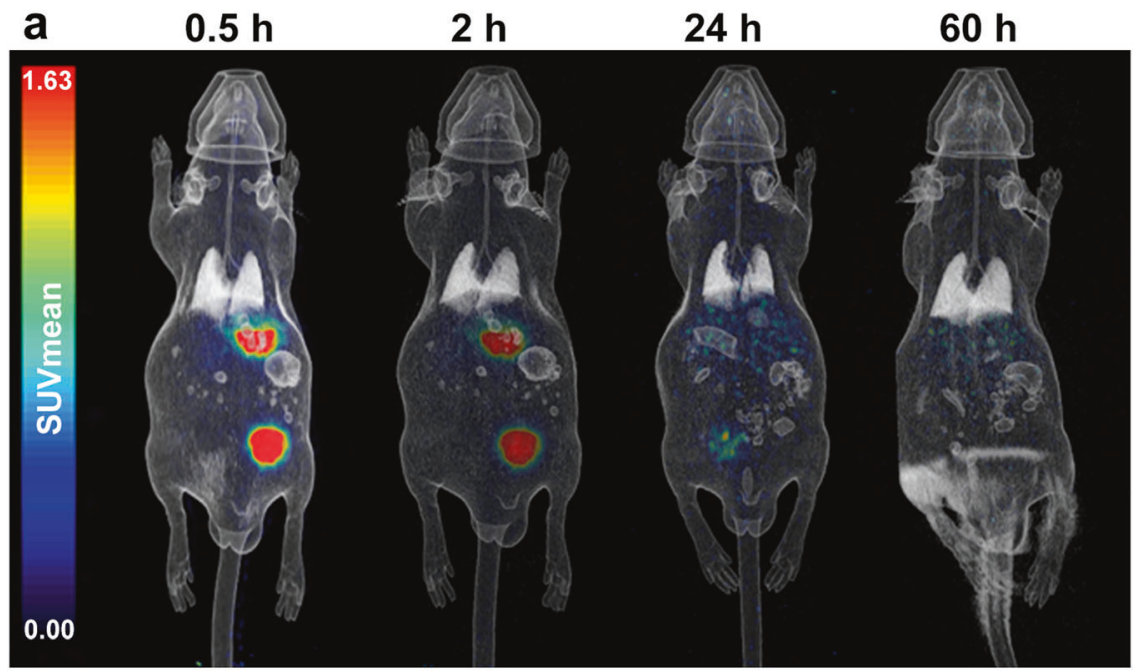

b

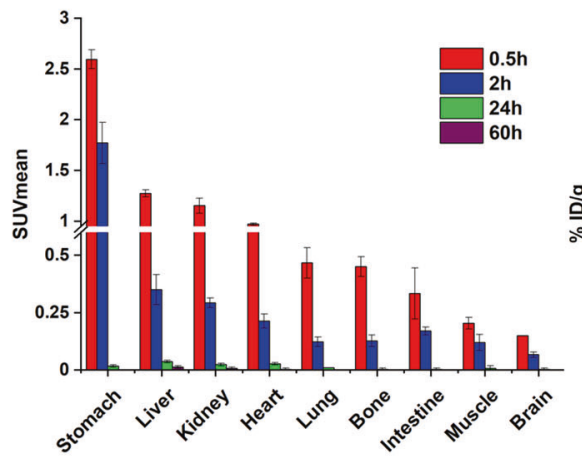

C

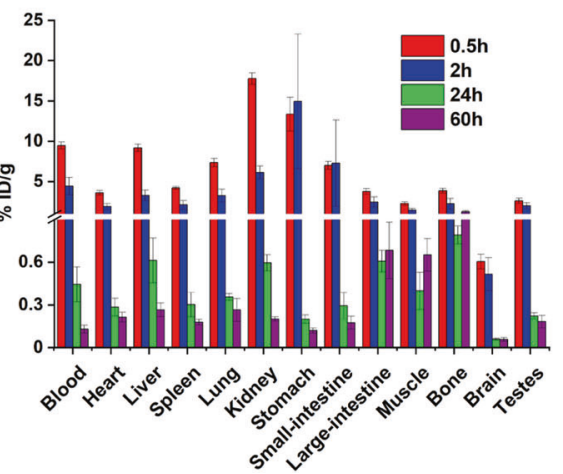

Fig. 3 Micro-PET imaging of ${ }^{124}$ I-RBD. a Micro-PET/CT imaging of ${ }^{124} \mathrm{I}$-RBD in normal mice at $0.5,2,24,60 \mathrm{~h}$ after tail vein injection. b SUV value of vital organs at different time points. c The biodistribution of ${ }^{124}$ I-RBD in normal mice. 


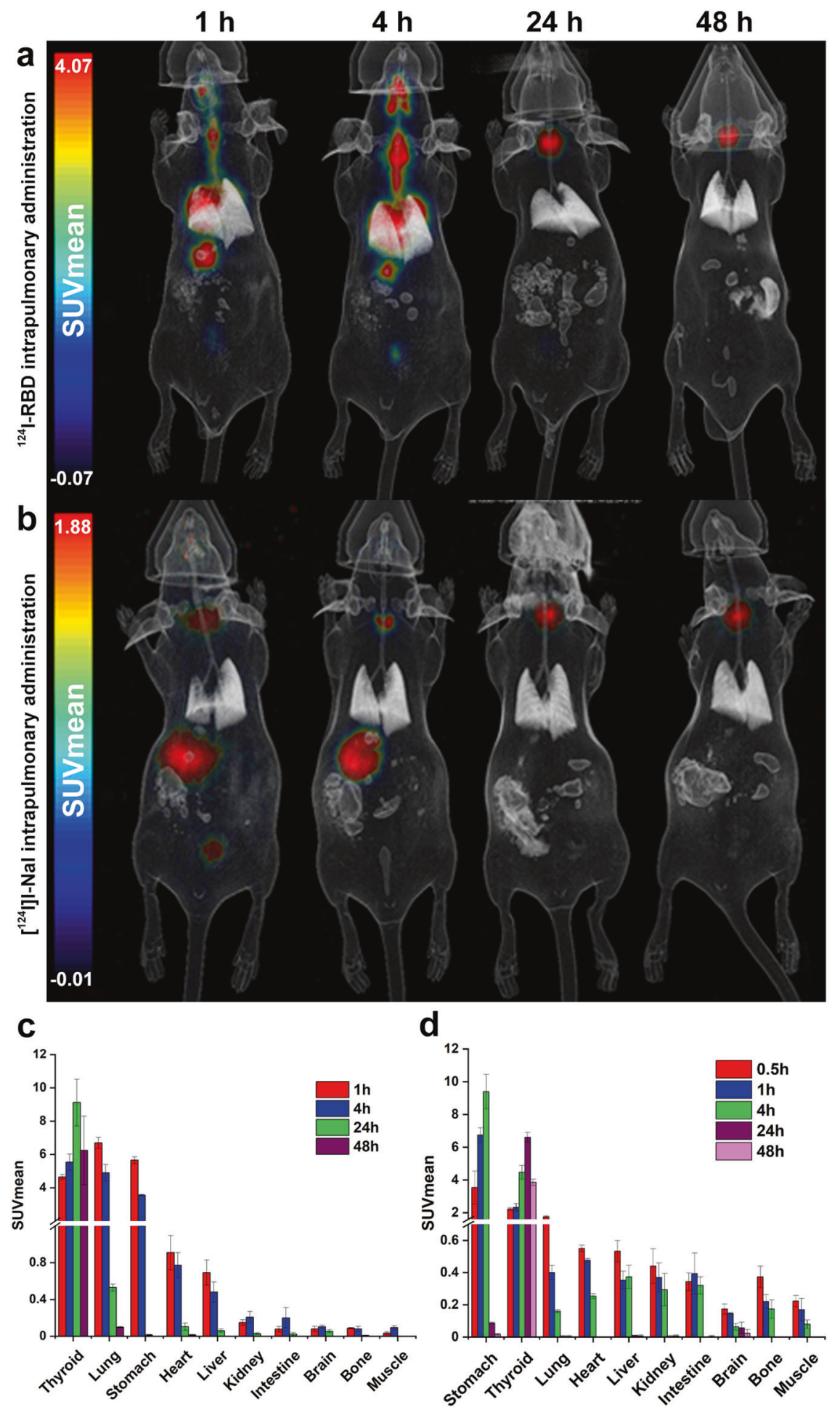

Fig. 4 Micro-PET imaging of ${ }^{124}$ I-RBD via intrapulmonary injection. a Micro-PET/CT imaging results of ${ }^{124}$ I-RBD in normal mice at $1,4,24,48$ $\mathrm{h}$ after intrapulmonary injection. b Micro-PET/CT imaging results of $\left.{ }^{[24} \mathrm{l}\right] \mathrm{Nal}$ in normal mice at $0.5,1,4,24,48 \mathrm{~h}$ after intrapulmonary injection. c SUV value of ${ }^{124} \mathrm{I}-\mathrm{RBD}$ in vital organs at different time points. d SUV value of $\left[{ }^{124} \mathrm{I}\right] \mathrm{Nal}$ in vital organs at different time points.

After intrapulmonary injection, PET/CT imaging showed that the lung retained a long period of high uptake for at least $4 \mathrm{~h}$ after the injection of ${ }^{124}$ I-RBD, and the SUV $_{\text {mean }}$ value of the lung was still high for $24 \mathrm{~h}$. At $0.5 \mathrm{~h}$ p.i., intrapulmonarily injected [ $\left.{ }^{124} \mathrm{I}\right] \mathrm{Nal}$ could be observed in the lung, but the SUV ${ }_{\text {mean }}$ value in the lung decreased to very low level at $1 \mathrm{~h}$, indicating the specific interaction. Compared to nude mice, mice bearing HepG2 tumors
$\left(\mathrm{HepG} 2^{\mathrm{ACE} 2+}\right.$ ) showed higher uptake in tumor after ${ }^{124}$ I-RBD was injected through tail vein. At half an hour, the HepG $2^{\text {ACE2 }+}$ tumor site begins to uptake ${ }^{124} \mathrm{I}$-RBD, the concentration reaches a peak at $1 \mathrm{~h}$, then gradually decreases. At $4 \mathrm{~h}$, it still had a high uptake at the tumor site. As a proof of concept, we conclude the retention of ${ }^{124}$ I-RBD in the lung is caused by the specific binding of RBD to $A C E 2$, and it is useful for non-invasive mapping in body. 
a

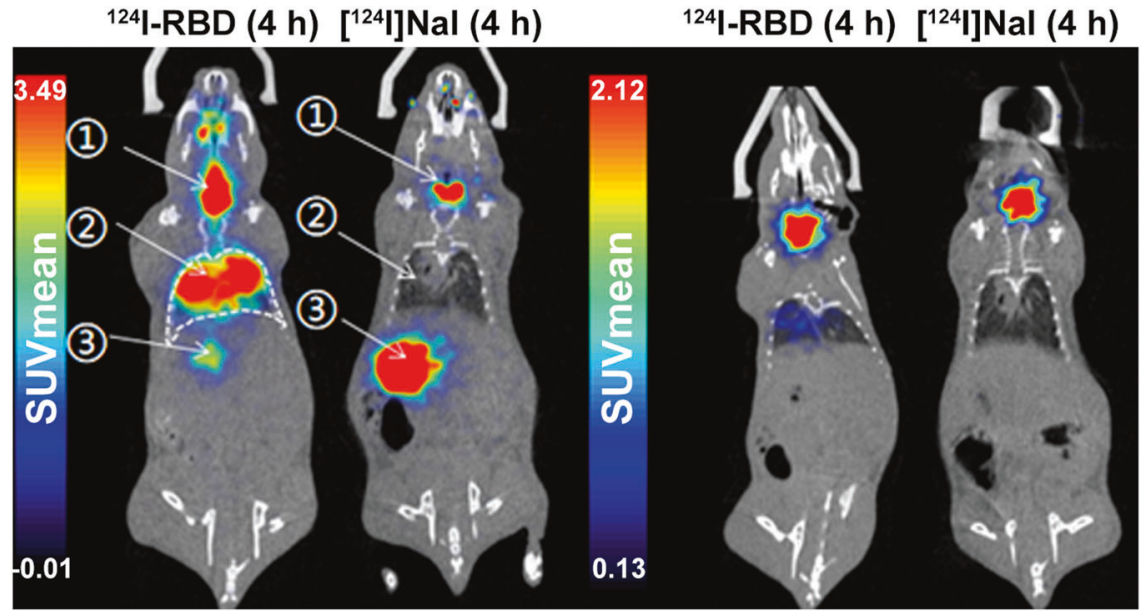

b

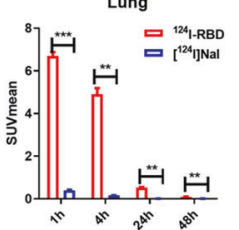

Kidney

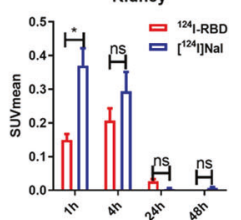

d
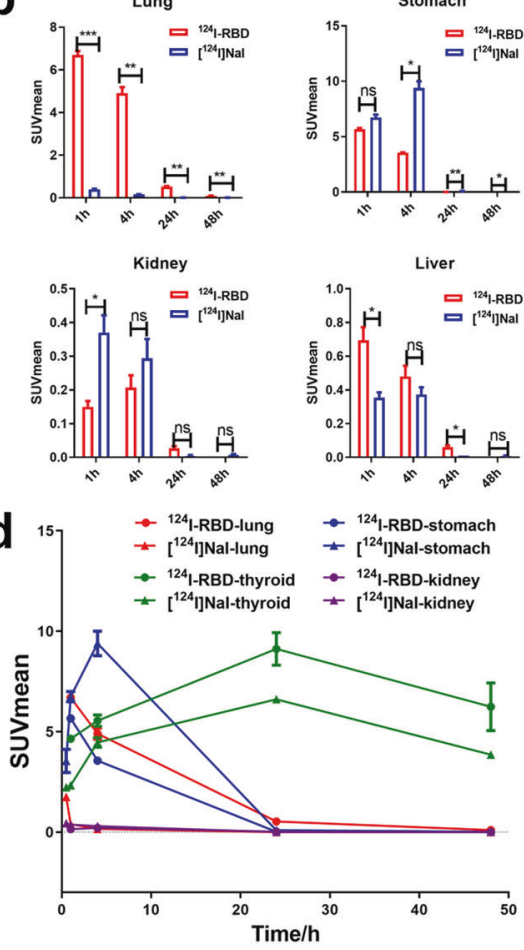

Liver

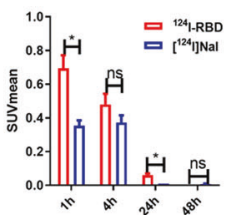

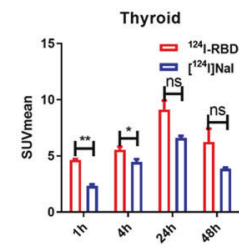

C
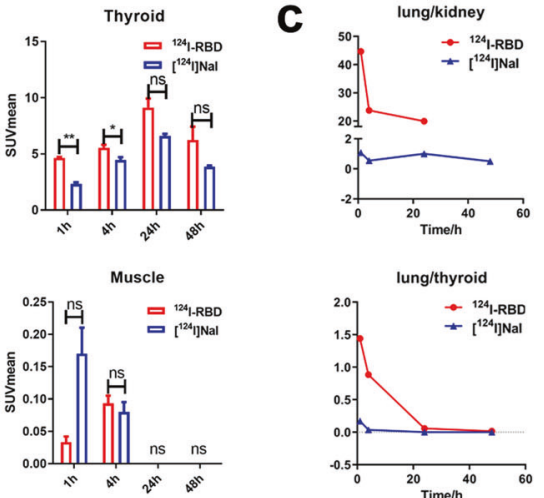

e

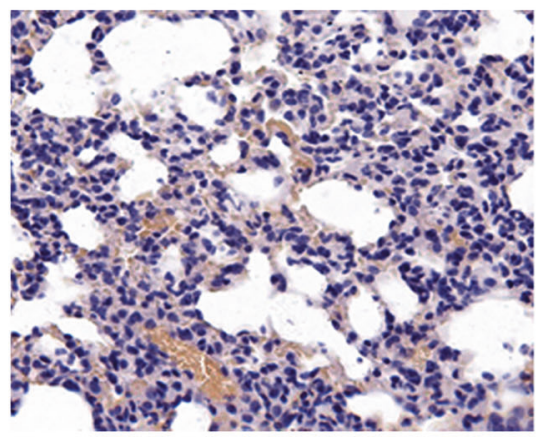

Fig. 5 Analysis of Micro-PET imaging. a Slice images of lung uptake at $4 \mathrm{~h}$ and $24 \mathrm{~h}$ after intrapulmonary injection of ${ }^{124} \mathrm{I}-\mathrm{RBD}$ and control $\left[{ }^{124}\right.$ I] Nal. (1), (2), (3) represent thyroid, lung and stomach of mice respectively. b The SUV changes of ${ }^{124}$ I-RBD in lung, stomach, thyroid, kidney, liver, muscle and other organs as well as the control $\left[{ }^{124} \mathrm{l}\right] \mathrm{Nal}$ at different time points. c Ratio of lung SUV to kidney and thyroid at different time points of ${ }^{124}$ I-RBD and control [ ${ }^{124} \mathrm{I}$ ]Nal. d The SUV of ${ }^{124} \mathrm{I}$-RBD and control [ ${ }^{124} \mathrm{I}$ ]Nal in vital organs over time. Small animal PET/CT imaging was performed at $1,4,24$ and $48 \mathrm{~h}$ after injection of ${ }^{124} \mathrm{I}-\mathrm{RBD}$ in mice, and $\left.{ }^{124} \mathrm{I}\right] \mathrm{Nal}$ increased the imaging time by $0.5 \mathrm{~h}$. e Immunohistochemistry of mouse lung tissue showed the expression of ACE2 in the lungs.

The biodistribution study of ${ }^{124}$ I-RBD demonstrated favorable pharmacokinetics with a relatively short half-life in vivo (Fig. 3c). Human organ radiation dosimetry was estimated by the biodistribution data of ${ }^{124}$ I-RBD using the OLINDA/EXM 2.0 software package. Osteogenic cells are the most critical component with the radiation dosimetry value of $0.242 \mathrm{mGy} / \mathrm{MBq}$, followed by red marrow, spleen, left colon and small intestine. The overall effective dose was $0.0642 \mathrm{mSv} / \mathrm{MBq}$, indicating the effective dose that one human subject takes in is $4.80 \mathrm{mSv}$ when injected with $74.8 \mathrm{MBq}$ of ${ }^{124} \mathrm{I}-\mathrm{RBD}$ (Table 2). It is within reasonable limits.

Recently, Pillarsetty et al. reported a human-derived antibody CR3022 that binds to the SARS-CoV-2 virus [11]. CR3022 was labeled with ${ }^{125} \mathrm{I}$ and its binding ability was tested in an attempt to expand its potential application in molecular targeted radiotherapy. For molecular targeted internal radiation therapy, the type of radioactivity is critical. Radionuclide-based radiotherapy can break the single-stranded nucleic acid but cannot easily change the double- stranded structure of DNA [9]. This property of iodine isotopes helps to achieve the goal of killing or inhibiting virus replication in cells without affecting normal cells to the greatest extent. To achieve this goal, it is obviously an excellent means to use ${ }^{124}$ I-labeled targeting drugs to locate the target ACE2 precisely. We also supposed that, iodine-labeled RBD may also be used as radiotherapy agent that binds well to ACE2, like "beat SARS-CoV-2's swords into plowshares". As isotopes of iodine, ${ }^{123} \mathrm{I},{ }^{125} \mathrm{I}$, and ${ }^{131} \mathrm{I}$ labeled RBD was subjected to radiation dose estimation by the hypothesis that [123/124/125/131 I]I-RBD shares the same biodistribution results. ${ }^{123}$ I-RBD, ${ }^{125}$ I-RBD and ${ }^{131}$ I-RBD showed a similar organ radiation injury risk with lower effective dose of $0.0106,0.00564$ and $0.0379 \mathrm{mSv} / \mathrm{MBq}$ (Table 2). 


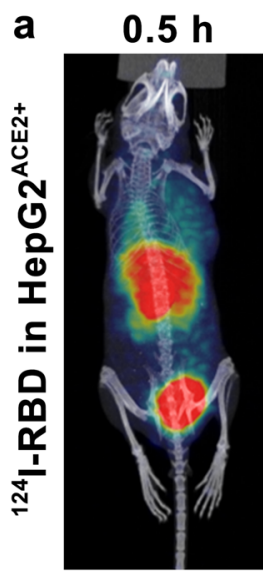

$1 \mathrm{~h}$

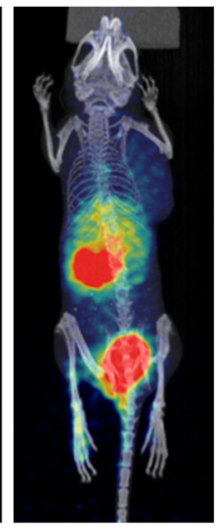

$2 \mathrm{~h}$
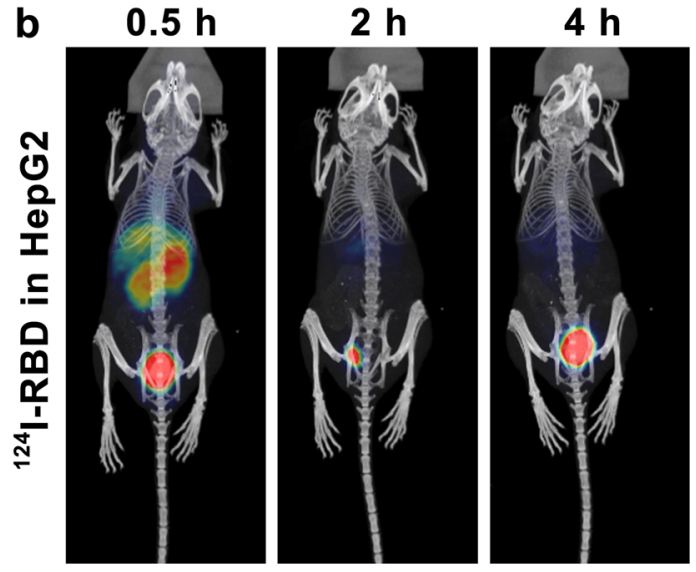

$24 \mathrm{~h}$

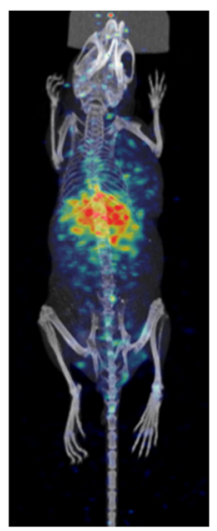

$24 \mathrm{~h}$
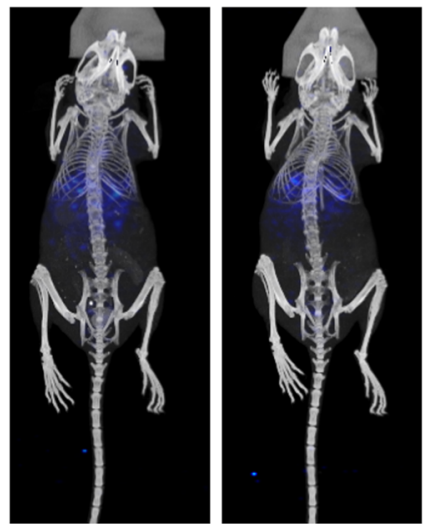
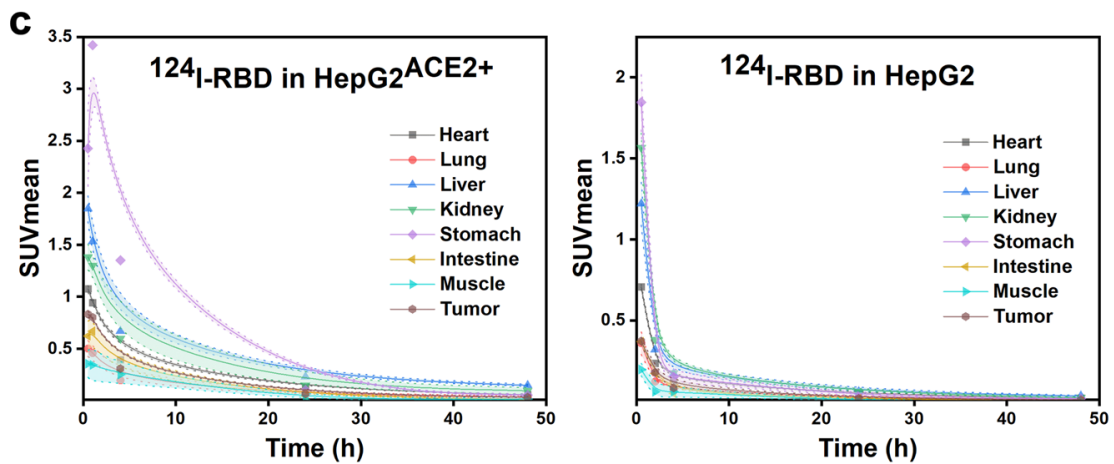

Fig. 6 Micro-PET imaging of tumor models. a Micro-PET/CT imaging of ${ }^{124} \mathrm{I}-\mathrm{RBD}$ in ACE2 expressing HepG2 tumor-bearing mice at 0.5 $(2.2 / 1.1), 1(2.2 / 1.1), 4(1.2 / 0.6), 24(0.36 / 0.18)$ and $48 \mathrm{~h}(0.36 / 0.18)$ post-injection. b Micro-PET/CT imaging of ${ }^{124}$ I-RBD in HepG2 tumor-bearing mice at $0.5(2.2 / 1.1), 2(2.2 / 1.1), 4(1.2 / 0.6), 24(0.36 / 0.18)$ and $48 \mathrm{~h}(0.36 / 0.18)$ post-injection. c Comparison of the SUVmean of Micro-PET imaging at each time post-injection. Heart, liver, lung, kidney, stomach, intestine, muscle and tumor were selected for both group ( $n=3$ ). The window widths and levels are different according to time points, and were listed in brackets after time points.

At present, the iodine isotopes have been used in the clinical diagnosis and treatment of certain types of solid tumors, and has been widely used in nuclear imaging research. Intuitively speaking, ${ }^{124}$ I radio-labeled RBD may be applied beyond the in vivo, real-time, non-invasive imaging of SARS-CoV-2 invasion of the human body.

As for the current therapy strategy of COVID-19, in addition to vaccines, neutralizing antibody and small molecule antivirals are tools that are expected to reduce the critical and fatality rates of COVID-19. A successful development of an antiviral drug means that the COVID-19 could become a treatable disease or significantly reduce public fear. But more than a year and a half after the COVID-19 outbreak, there is still no satisfactory effective drugs available globally.
On October 22, 2020, remdesivir [13] obtained FDA approval for the treatment of hospitalized patients over 12 years of age and weighing more than 40 kilograms. Since then, no small-molecule antiviral drug targeting the SARS-CoV-2 has been approved worldwide. Merck \& Co.'s Molnupiravir [14] is currently in the clinical stage, which uses a unique mechanism to destroy the virus. Because its molecular structure is similar to RNA nucleotides, the virus lacks a mechanism to identify them, then mistakes it for qualified material when they replicate, resulting in viral RNA with no biological activity. Finally, the virus stops from replicating. Antiviral agents are much less affected by the mutant strains than by the SARS-CoV-2 vaccine. So far, the mutant virus has occurred only structural changes, other than mutation that bypasses the molnupiravir mechanism. 
Table 2. Estimated human organ absorbed radiation dosimetry of ${ }^{124}$ I-RBD.

\begin{tabular}{|c|c|c|c|c|}
\hline \multirow[t]{2}{*}{ Organ } & \multicolumn{4}{|c|}{ Equivalent dose (mGy/MBq) } \\
\hline & $\overline{124 \text { I-RBD }}$ & ${ }^{123}$ I-RBD & ${ }^{125} \mathrm{I}-\mathrm{RBD}$ & ${ }^{131}$ I-RBD \\
\hline Adrenals & $5.56 \times 10^{2}$ & $9.39 \times 10^{3}$ & $3.72 \times 10^{3}$ & $2.74 \times 10^{2}$ \\
\hline Brain & $4.92 \times 10^{2}$ & $8.67 \times 10^{3}$ & $4.31 \times 10^{3}$ & $2.59 \times 10^{2}$ \\
\hline Esophagus & $4.69 \times 10^{2}$ & $8.05 \times 10^{3}$ & $3.58 \times 10^{3}$ & $2.42 \times 10^{2}$ \\
\hline Eyes & $4.84 \times 10^{2}$ & $8.50 \times 10^{3}$ & $4.20 \times 10^{3}$ & $2.47 \times 10^{2}$ \\
\hline Gallbladder wall & $4.80 \times 10^{2}$ & $8.26 \times 10^{3}$ & $3.39 \times 10^{3}$ & $2.49 \times 10^{2}$ \\
\hline Left colon & $5.92 \times 10^{2}$ & $1.02 \times 10^{2}$ & $4.49 \times 10^{3}$ & $3.28 \times 10^{2}$ \\
\hline Small intestine & $5.75 \times 10^{2}$ & $9.90 \times 10^{3}$ & $4.30 \times 10^{3}$ & $3.20 \times 10^{2}$ \\
\hline Stomach wall & $4.33 \times 10^{2}$ & $7.09 \times 10^{3}$ & $2.81 \times 10^{3}$ & $2.32 \times 10^{2}$ \\
\hline Right colon & $5.18 \times 10^{2}$ & $8.79 \times 10^{3}$ & $3.63 \times 10^{3}$ & $2.82 \times 10^{2}$ \\
\hline Rectum & $5.38 \times 10^{2}$ & $9.42 \times 10^{3}$ & $3.94 \times 10^{3}$ & $2.70 \times 10^{2}$ \\
\hline Heart wall & $4.33 \times 10^{2}$ & $7.49 \times 10^{3}$ & $2.99 \times 10^{3}$ & $2.11 \times 10^{2}$ \\
\hline Kidneys & $4.81 \times 10^{2}$ & $8.20 \times 10^{3}$ & $3.44 \times 10^{3}$ & $2.51 \times 10^{2}$ \\
\hline Liver & $3.87 \times 10^{2}$ & $6.60 \times 10^{3}$ & $2.59 \times 10^{3}$ & $1.92 \times 10^{2}$ \\
\hline Lungs & $4.35 \times 10^{2}$ & $7.84 \times 10^{3}$ & $3.76 \times 10^{3}$ & $2.32 \times 10^{2}$ \\
\hline Pancreas & $5.10 \times 10^{2}$ & $8.85 \times 10^{3}$ & $3.53 \times 10^{3}$ & $2.61 \times 10^{2}$ \\
\hline Prostate & $4.91 \times 10^{2}$ & $8.48 \times 10^{3}$ & $3.53 \times 10^{3}$ & $2.53 \times 10^{2}$ \\
\hline Salivary glands & $4.85 \times 10^{2}$ & $8.39 \times 10^{3}$ & $3.70 \times 10^{3}$ & $2.49 \times 10^{2}$ \\
\hline Red marrow & $1.70 \times 10^{1}$ & $2.17 \times 10^{2}$ & $1.22 \times 10^{2}$ & $1.15 \times 10^{1}$ \\
\hline Osteogenic cells & $2.42 \times 10^{1}$ & $1.25 \times 10^{1}$ & $1.93 \times 10^{1}$ & $2.83 \times 10^{1}$ \\
\hline Spleen & $5.93 \times 10^{2}$ & $1.04 \times 10^{2}$ & $5.31 \times 10^{3}$ & $3.56 \times 10^{2}$ \\
\hline Testes & $4.24 \times 10^{2}$ & $6.93 \times 10^{3}$ & $3.08 \times 10^{3}$ & $2.25 \times 10^{2}$ \\
\hline Thymus & $4.44 \times 10^{2}$ & $7.56 \times 10^{3}$ & $3.42 \times 10^{3}$ & $2.33 \times 10^{2}$ \\
\hline Thyroid & $4.82 \times 10^{2}$ & $8.34 \times 10^{3}$ & $3.69 \times 10^{3}$ & $2.48 \times 10^{2}$ \\
\hline Urinary bladder wall & $4.91 \times 10^{2}$ & $8.49 \times 10^{3}$ & $3.53 \times 10^{3}$ & $2.53 \times 10^{2}$ \\
\hline Total body & $5.58 \times 10^{2}$ & $1.01 \times 10^{2}$ & $5.35 \times 10^{3}$ & $3.19 \times 10^{2}$ \\
\hline Effective dose (mSv/MBq) & $6.42 \times 10^{2}$ & $1.06 \times 10^{2}$ & $5.64 \times 10^{3}$ & $3.79 \times 10^{2}$ \\
\hline
\end{tabular}

Neutralizing antibodies are another important means of preventing critical cases, but they also face the challenges of mutant strains and high costs. In principle, neutralizing antibodies can recognize viral surface proteins and block the binding of viruses to specific receptors on cell surfaces. But compared to antiviral drugs, which can directly eliminate the virus, neutralizing antibodies can only block the virus infecting cells and prevent it from getting worse. On July 30, 2021, the FDA approved the emergency use of the new neutralizing antibody REGEN-COV [15] for prophylaxis after exposure to a virus-containing environment. REGEN-COV is developed by Regeneron Pharmaceuticals, available for people with high risk to develop critical cases, including unvaccinated people, poor vaccination effect, and so on. However, due to the small number of cases in clinical studies, the effect of neutralizing antibodies in the prevention of critical cases need to be further observed.

To sum up, it's safe to comment that despite the physiological characteristics of the monoclonal antibody lead to a longer halflife of the drug in the body, the long radiation half-life of ${ }^{124}$ I is well in line with it. On the other hand, the longer residence time in the tumor and the extreme small drug dose will simultaneously benefit the targeting and safety of cancer therapy by radio probe. In order to better develop the application of this probe in the diagnosis and treatment of COVID-19 patients and cancer patients, more clinical trials and various kinds of tumor case studies are needed.

\section{CONCLUSION}

Here, we successfully constructed ${ }^{124} \mathrm{I}-\mathrm{RBD}$, for the first time, as a novel molecular targeting probe for COVID-19. The probing of ACE2 expression via radiolabeled RBD can be used for non-invasive ACE2 mapping. In combination with the available literature, it can be suggested that human-ACE2 targeting monitoring is feasible using iodine isotope modified RBD, which supplies preclinical experience for radiotherapy.

\section{ACKNOWLEDGEMENTS}

We thank the cyclotron teams of the Department of Nuclear Medicine, Peking University Cancer Hospital \& Institude for ${ }^{124}$ I production. The current research was financially supported by the National Science and Technology Major Project (No. 2020ZX09201023), Beijing Municipal Administration of Hospitals-Yangfan Project (ZYLX201816), Beijing Excellent Talents Funding (2017000021223ZK33), Beijing Millions of Talent Projects A Level Funding (No. 2019A38) and by Key laboratory of Carcinogenesis and Translational Research, Ministry of Education/ Beijing(2019 Open Project- 06).

\section{ADDITIONAL INFORMATION}

Supplementary information The online version contains supplementary material available at https://doi.org/10.1038/s41401-021-00809-y.

Competing interests: The authors declare no competing interests.

\section{REFERENCES}

1. Borba MGS, Val FFA, Sampaio VS, Alexandre MAA, Melo GC, Brito M, et al. Effect of high vs low doses of chloroquine diphosphate as adjunctive therapy for patients hospitalized with severe acute respiratory syndrome coronavirus 2 (SARS-CoV-2) infection: a randomized clinical trial. JAMA Netw Open. 2020;3:e208857.

2. Shi Y, Wang Y, Shao C, Huang J, Gan J, Huang X, et al. COVID-19 infection: the perspectives on immune responses. Cell Death Differ. 2020;27:1451-4.

3. Zhao Y, Zhao Z, Wang Y, Zhou Y, Ma Y, Zuo W. Single-cell RNA expression profiling of ACE2, the receptor of SARS-CoV-2. Am J Respir Crit Care Med. 2020; 202:756-9.

4. Hoffmann M, Kleine-Weber $H$, Schroeder S, Krüger N, Herrler T, Erichsen $S$, et al. SARS-CoV-2 cell entry depends on ACE2 and TMPRSS2 and is blocked by a clinically proven protease inhibitor. Cell. 2020;181:271-280.e8.

5. Chen WG, Dilsizian D. Molecular imaging of cardiovascular device infection: targeting the bacteria or the host-pathogen immune response? J Nucl Med. 2020; 61:319-26.

6. Ordonez AA, Sellmyer MA, Gowrishankar G, Ruiz-Bedoya CA, Tucker EW, Palestro $\mathrm{CJ}$, et al. Molecular imaging of bacterial infections: overcoming the barriers to clinical translation. Sci Transl Med. 2019;11:eaax8251.

7. Tucker EW, Guglieri-Lopez B, Ordonez AA, Ritchie B, Klunk MH, Sharma R, et al. Noninvasive ${ }^{11} \mathrm{C}$-rifampin positron emission tomography reveals drug biodistribution in tuberculous meningitis. Sci Transl Med. 2018;10:eaau0965.

8. Jadvar H. Targeted radionuclide therapy: an evolution toward precision cancer treatment. Am J Roentgenol. 2017;209:277-88.

9. Parliament MB, Murray D. Single nucleotide polymorphisms of DNA repair genes as predictors of radioresponse. Semin Radiat Oncol. 2010;20:232-40.

10. Huang HF, Zhu H, Li GH, Xie Q, Yang XT, Xu XX, et al. Construction of Anti-hPD-L1 $\mathrm{HCAb} \mathrm{Nb6}$ and in Situ ${ }^{124}$ I labeling for noninvasive detection of PD-L1 expression in human bone sarcoma. Bioconjug Chem. 2019;30:2614-23.

11. Pillarsetty N, Carter LM, Lewis JS, Reiner T. Oncology-inspired treatment options for COVID-19. J Nucl Med. 2020;61:1720-3.

12. Tang GH, Tang XL, Wang MF, Luo L, Gan MQ. O-(2-[18 F]fluoroethyl)-L-tyrosine radiation absorbed dose estimation in human body. J Isotopes. 2004;02:69-73.

13. Beigel JH, Tomashek KM, Dodd LE, Mehta AK, Zingman BS, Kalil AC, et al. Remdesivir for the treatment of Covid-19 - final report. N Engl J Med. 2020; 383:1813-26.

14. Menéndez-Arias L. Decoding molnupiravir-induced mutagenesis in SARS-CoV-2. J Biol Chem. 2021;297:100867.

15. O'Brien MP, Forleo-Neto E, Musser BJ, Isa F, Chan KC, Sarkar N, et al. Subcutaneous REGEN-COV antibody combination for Covid-19 prevention. medRxiv [Preprint]. 2021 Jun:2021.06.14.21258567. Update in: N Engl J Med. 2021 Aug 4. 